\title{
O ethos da auto-ajuda
}

\section{Anna Flora Brunelli UNESP/PG UNICAMP}

\section{Abstract}

In this paper, based on French Discourse Analysis, following the theory developed by Maingueneau, we investigate the ethos of self-help counselling literature, by analysing the enunciative characteristics of this discourse. The analysis reveals that the ethos of self-help counselling literature is the ethos of the confident and trustful man, the man who has no fears, no doubts and never complains, because he deeply belives in his own success. This kind of man is also a man of a action, who is always concentrated on his owns attairs. The analysis also reveals that self-help couselling literature promotes its owns enunciative characteristics. 


\section{INTRODUÇÃO}

$\mathrm{N}$

o interior do que costumeiramente se chama de Análise do Discurso francesa (AD, doravante), a abordagem de Maingueneau (1998) se distancia de outras propostas de investigação dos discursos essencialmente pela forma de lidar com a questão da heterogeneidade constitutiva dos discursos. Enquanto os trabalhos que se inscrevem na linha teórica de Pêcheux e de Courtine estão mais voltados para a definição de classes de seqüências parafrásticas de um mesmo enunciado no interdiscurso, Maingueneau, partindo do princípio de que a identidade de uma formação discursiva vem da relação com o Outro, propõe que uma formação discursiva deve ser apreendida como uma interação entre formações discursivas. Segundo o autor, isso implica que

“a identidade discursiva está construída na relação com o Outro. Não
se distinguirão, pois, duas partes (...) a saber, as formações
discursivas por um lado, e suas relações por outro, mas entender-
se-á que todos os elementos são retirados da interdiscursividade.
Mesmo na ausência de qualquer marca de heterogeneidade
mostrada, toda unidade de sentido, qualquer que seja seu tipo, pode
estar inscrita em uma relação essencial com uma outra, aquela do
ou dos discursos em relação aos quais o discurso de que ela deriva
define sua identidade. (...) Dizer que a interdiscursividade é
constitutiva é também dizer que um discurso não nasce, como
geralmente é pretendido, de algum retorno às próprias coisas, ao
bom senso, etc., mas de um trabalho sobre outros discursos."
(MAINGUENEAU, 1989, p. 119-120)

Partindo da tese do primado do interdiscurso, Maingueneau concebe o discurso como um "sistema de regras que define a 
especificidade de uma enunciação" (ibid., p. 4), estabelecendo, para a sua apreensão, um método de análise que se revela como um "sistema no qual a definição da rede semântica que circunscreve a especificidade de um discurso coincide com a definição das relações desse discurso com seu Outro" (ibid., p. 16).

Tendo em vista que Maingueneau define o discurso como um sistema de restrições semânticas globais, isto é, um conjunto de traços semânticos que restringe, ao mesmo tempo, todos os planos do discurso (vocabulário, temas tratados, intertextualidade, instâncias de enunciação etc.), podemos dizer que a sua abordagem também se distingue de outras por ser mais abrangente. Voltada para a exploração do discurso em toda a sua complexidade, procura apreendê-lo sem privilegiar um ou outro de seus planos, "mas integrando-os todos de uma vez, tanto na ordem do enunciado quanto na da enunciação" (MAINGUENEAU, 1998, p. 45). A esse respeito, o autor afirma:

Qualquer leitor ou ouvinte um pouco atento percebe muito bem que a identidade de um discurso não é somente uma questão de vocabulário ou de proposições, que ela depende de fato de uma coerência global que integra múltiplas dimensões textuais, mas as análises que propomos dela não se ocupam nunca disso. (ibid., p. 3)

Essencialmente, Maingueneau investe contra "a idéia de que há, no interior do funcionamento discursivo, um lugar onde sua especificidade se condensaria de maneira exclusiva ou privilegiada que fosse (as palavras, as frases, os agenciamentos argumentativos, etc.)" (ibid., p. 6). O que se busca nessa perspectiva é apreender o dinamismo da significância que domina toda a discursividade. Segundo Maingueneau, isso envolve não só o enunciado, mas também a enunciação. Por isso, para o autor, a enunciabilidade de um discurso, isto é,

"o fato de que tenha sido objeto de atos de enunciação por um conjunto de indivíduos não é uma propriedade que lhe é atribuída por acréscimo, mas alguma coisa radical, que condiciona toda sua 
estrutura. É preciso pensar ao mesmo tempo a discursividade como dito e como dizer, enunciado e enunciação" (ibid., p. 4; o grifo é nosso).

Entendemos, portanto, que uma análise inscrita nessa perspectiva encontra, nas dimensões discursivas voltadas para a problemática da enunciação (dêixis discursiva, estatuto dos interlocutores do discurso, ethos discursivo), um terreno fértil para a compreensão do sistema de restrições semânticas que define o discurso investigado.

Como o nosso objetivo é justamente desenvolver uma análise do discurso da auto-ajuda, seguindo a proposta de Maingueneau, neste trabalho iremos discutir as características do ethos desse discurso, procurando relacioná-las às restrições semânticas que as autorizam.

Antes, porém, gostaríamos de destacar que, segundo Maingueneau, os semas que constituem a grade semântica definidora de um discurso qualquer estão repartidos em dois registros: o registro dos semas positivos, reivindicados pelo discurso, e o dos semas negativos, rejeitados por ele. Na prática, isso significa que enunciar a partir de uma determinada formação enunciativa é enunciar em conformidade com as regras dessa formação e rejeitar o que seriam ${ }^{1}$ os traços semânticos de seu Outro, seja ele um discurso atestado ou virtual. Nesse sentido, procuraremos revelar, no estudo do ethos do discurso da auto-ajuda, os traços semânticos que esse estudo reivindica e os que rejeita.

\section{FORMAÇÃO DISCURSIVA E ETHOS: DA INCORPORAÇÃO À INTERPELAÇÃO}

Maingueneau entende por ethos o conjunto de características relacionadas ao sujeito-enunciador do discurso revelado pelo próprio modo como esse sujeito enuncia. Trata-se, portanto, não do que esse sujeito diz a respeito de si, mas a personalidade que mostra pelo modo de se exprimir (cf. MAINGUENEAU, 1995, cap. 7). 
Afastando-se de qualquer concepção voluntarista de ethos "de acordo com a qual o enunciador, à semelhança do autor, desempenharia o papel de sua escolha em função dos efeitos que pretende produzir em seu auditório" (MAINGUENEAU, 1989, p. 45), Maingueneau nos esclarece que o ethos, como parte integrante de uma formação discursiva qualquer, assim como outras dimensões da discursividade, é imposto por ela àquele que, em seu interior, assume um lugar de enunciação. A esse respeito, Maingueneau afirma:

O etos está, dessa maneira, vinculado ao exercício da palavra, ao papel que corresponde a seu discurso, e não ao indivíduo "real", apreendido independentemente de seu desempenho oratório: é, portanto, o sujeito de enunciação enquanto está enunciando que está em jogo aqui. (MAINGUENEAU, 1995, p. 138; o grifo é nosso)

Com o ethos, o co-enunciador tem condições de formar, por meio de índices de várias ordens fornecidos pelo texto, uma representação do sujeito-enunciador que, por sua vez, desempenha o papel de um fiador ${ }^{2}$ encarregado da responsabilidade do texto.

O primeiro elemento que recobre o campo do ethos enunciativo é a voz do discurso cuja concepção é transversal à oposição entre o oral e o escrito. Isso significa que não se trata de conceber o escrito como uma oralidade enfraquecida, como se fosse o "vestígio, o pálido reflexo de uma oralidade primeira" , mas de entender que há uma voz específica que habita a enunciação do texto. A essa voz, Maingueneau prefere chamar de tom "à medida que seja possível falar do 'tom' de um texto do mesmo modo que se fala de uma pessoa" (MAINGUENEAU, 1989, p. 46). Descartando qualquer hierarquia entre o dito e a maneira de dizê-lo, o autor considera que "o que é dito e o tom com que é dito são igualmente importantes e inseparáveis" (ibid., p. 46).

O tom, entendido como um ideal de entonação que acompanha os lugares de enunciação, está ligado a um caráter e a uma corporalidade. O caráter 
corresponde a este conjunto de traços "psicológicos" que o leitorouvinte atribui espontaneamente à figura do enunciador, em função de seu modo de dizer. (...) Bem entendido, não se trata aqui de caracterologia, mas de estereótipos que circulam em uma cultura determinada. Deve-se dizer o mesmo a propósito da "corporalidade", que remete a uma representação do corpo do enunciado da formação discursiva. Corpo que não é oferecido ao olhar, que não é uma presença pela, mas uma espécie de fantasma induzido pelo destinatário como correlato de sua leitura. Os discursos se opõem sobre essa dimensão como sobre as outras; há "caracteres" e "corporalidades" específicas dos enunciadores do Figaro, de l'Humanité ou Libération, (...), e estas divergências remetem aos próprios fundamentos destes discursos (ibid., p. 47).

Segundo Maingueneau, a corporalidade está associada a uma compleição do corpo do sujeito-enunciador, que é inseparável de um modo de se movimentar no espaço social, o que pode incluir até um modo de se vestir. Nesse sentido, o ethos é uma maneira de dizer indissociável de uma maneira global de ser, de uma maneira de habitar o mundo.

Entre as diversas dimensões da discursividade, podemos dizer que o ethos tem um status especial, tendo em vista que, segundo Maingueneau, ele está diretamente ligado à questão da eficácia de um discurso, isto é, da sua capacidade de suscitar a crença. Para explicitar o papel do ethos no processo de adesão dos sujeitos ao discurso, Maingueneau introduz a noção de incorporação, que designa a integração entre uma formação discursiva e seu ethos, mediada pela enunciação. Essa incorporação, constituída sobre o poder que a voz tem de exprimir a interioridade do enunciador e envolver o co-enunciador, atua sobre três registros estreitamente articulados:

- a formação discursiva confere "corporalidade" à figura do enunciador e, correlativamente, àquela do destinatário, ela lhes dá "corpo" textualmente;

- esta corporalidade possibilita aos sujeitos a "incorporação" de esquemas que definem uma maneira específica de habitar o mundo, a sociedade; 
- estes dois primeiros aspectos constituem uma condição da "incorporação" imaginária dos destinatários ao corpo, o grupo dos adeptos do discurso (ibid., p. 48).

Por intermédio da passagem acima, podemos perceber que o co-enunciador não adere a um discurso simplesmente porque lhe é apresentado um conjunto de idéias ligadas a seus possíveis interesses; na verdade, “é alguém que tem acesso ao ‘dito’ através de uma 'maneira de dizer' que está enraizada em uma 'maneira de ser', o imaginário de um vivido" (ibid., p. 49). Nesse sentido, as formações discursivas conquistam a adesão dos sujeitos legitimando, atestando o que é dito na própria enunciação, o que permite que esses sujeitos se identifiquem com uma certa determinação do corpo. A esse respeito, Maingueneau afirma:

El poder de persuasión de un discurso proviene en parte de un hecho básico: lleva al lector a identificarse con los movimientos de un cuerpo investido de valores especificados históricamente. La condición del ethos remite en efecto a la figura de ese "garante" que, a través del habla, se forja una identidada a la medida del mundo que hace surgir de su enunciado. Paradoja constitutiva: el garante debe legitimar su manera de decir a través de su propio enunciado. (MAINGUENEAU, 1996, p. 82)

Conforme destaca o próprio Maingueneau, a noção de incorporação nos possibilita compreender melhor a noção althusseriana de assujeitamento, à qual a $\mathrm{AD}$ freqüentemente recorre, para justificar a adesão dos sujeitos às formações discursivas, embora o funcionamento desse processo seja muito pouco claro.

Como se sabe, na $\mathrm{AD}$, o discurso é considerado como um dos aspectos materiais da materialidade ideológica, tendo em vista que as formações discursivas representam, na linguagem, as formações ideológicas que lhe são correspondentes. Por essa representação, a $\mathrm{AD}$ entende que são as formações discursivas que interpelam os indivíduos em sujeitos falantes, ou seja, em sujeitos de seus discursos. Porém faltava à AD justamente uma explicação para a forma como essa interpelação, esse chamamento é feito, explicação essa 
fornecida, conforme vimos, pelos três registros sobre os quais a incorporação atua. Dessa forma, a noção de incorporação nos possibilita compreender que a enunciação é a base do poder de assujeitar dos discursos, tendo em vista que é pelo seu modo de expressão que um discurso projeta o modo de habitar o mundo ao qual o co-enunciador precisa se identificar para aderir ao discurso.

Eagleton (1997) nos esclarece que a ideologia, para Althusser, se refere principalmente às nossas relações afetivas e inconsciente com o mundo, aos modos pelos quais estamos vinculados à realidade social. Longe de ser um mero conjunto de idéias abstratas, a ideologia é "a matéria da qual cada um de nós é feito, o elemento que constitui nossa identidade" (EAGLETON, 1997, p. 30). Nesse sentido, a noção de incorporação funciona como um esclarecimento a respeito do papel das formações discursivas na constituição dos sujeitos, uma vez que essas, ao projetarem uma maneira global de ser, fornecem as condições para a produção das formas de subjetividade.

A partir desses esclarecimentos, entendemos que, adotando a noção de incorporação, a AD consegue escapar da alternativa de explicar a adesão dos sujeitos aos discursos, por intermédio de projeções de estruturas sócioeconômicas, o que certamente é uma justificativa pouco adequada, tendo em vista que a leva a sustentar uma relação de exterioridade entre discurso e sociedade. Numa perspectiva oposta a essa, Maingueneau nos esclarece que o discurso não é uma doutrina, uma visão de mundo ou um depósito de conteúdos elaborados em outro lugar, mas "um dispositivo constitutivo da construção do sentido e dos sujeitos que aí se reconhecem" (MAINGUENEAU, 1989, p. 50). Assim, afirma que não existe essa suposta relação de exterioridade entre o funcionamento de um grupo e o de seu discurso. Para ele, as coerções que possibilitam um discurso são as mesmas que possibilitam o grupo que o sustenta. Como "as duas instâncias são conduzidas pela mesma lógica" ${ }^{4}$, Maingueneau rejeita a idéia de que o discurso seja gerado do exterior do grupo, e postula que a instituição discursiva apresenta duas faces: uma que diz respeito à linguagem e outra relacionada ao social. A 
partir dessa perspectiva, a AD consegue realizar o que Maingueneau entende como uma de suas tarefas, a saber: justificar como determinados enunciados conseguem mobilizar forças e investir em organizações sociais.

\section{O ETHOS DA AUTO-AJUDA}

Para a análise do ethos da auto-ajuda, estabelecemos um corpus constituído por livros escritos originalmente em Língua Portuguesa. Com isso evitamos a necessidade de adotarmos uma determinada teoria da tradução, compreendendo aí uma discussão das influências dos tradutores e de seus discursos nos textos em análise, o que estenderia muito os nossos objetivos. Tendo em vista a definição de discurso de que partimos, poderíamos perfeitamente basear nossas observações somente em uma publicação; entretanto, selecionamos um conjunto de cinco livros para enriquecer a exemplificação.

Conforme vimos no item anterior deste trabalho, Maingueneau entende por ethos as características do sujeito-enunciador reveladas pelo próprio modo como esse sujeito enuncia e não as que, porventura, ele mesmo atribua a si. Assim, para definirmos o ethos da auto-ajuda, iremos nos basear nas características enunciativas desse discurso às quais correlacionaremos a "personalidade" do sujeito-enunciador.

Os livros de auto-ajuda, de uma forma geral, pregam que o segredo para que qualquer um consiga melhorar de vida, alcançar o sucesso, ganhar muito dinheiro, etc. está na crença incondicional da realização dos sonhos, do projeto de vida, dos desejos, etc. Assim, quem acredita que vai conseguir, consegue, e quem duvida, não. Trata-se, pois, de uma questão de fé, de crença absoluta e, essencialmente, de jamais duvidar do poder que se tem de mudar a realidade. Como é uma questão de acreditar e de não duvidar, num trabalho anterior $^{5}$, examinando a modalidade na literatura de auto-ajuda, verificamos que o sujeito-enunciador desse tipo de discurso também 
manifesta, em seus textos, essa mesma crença/confiança que prega como necessária com relação às teses que propõe. Disso concluímos que a manifestação da certeza pode ser considerada um dos traços semânticos que caracterizam a auto-ajuda, na condição de um dos traços positivos que esse discurso reivindica, ao mesmo tempo em que a dúvida é um dos que rejeita e/ou evita. Essa conclusão se apóia especialmente no fato de que não encontramos nenhum registro de incerteza assumida pelo sujeito-enunciador dos enunciados analisados. Certo do que diz, esse sujeito-enunciador sempre se distancia de seus enunciados quando neles há marcas do possível (isto é, do incerto ou não garantido). A esse respeito, Chagas, analisando a literatura em questão, afirma que os livros de auto-ajuda trazem

na sua estrutura, conteúdos e convicções inabaláveis, como se, de fato, fossem experiências testadas e aprovadas pelas pessoas. Nesse discurso não existem indagações ou dúvidas. O que eles trazem é a resposta de uma promessa dogmática e definitiva (CHAGAS, 1999, p. 75; o grifo é nosso).

Temos, portanto, na auto-ajuda, um sujeito-enunciador que foge do terreno da incerteza e que se compromete incondicionalmente com as teses que enuncia, manifestando a certeza e a confiança que prega. Como reproduz em sua enunciação o modo de ser que propõe ao seu interlocutor, o sujeito-enunciador da autoajuda cumpre o que Maingueneau define como sendo o papel de qualquer sujeito-enunciador, isto é, legitimar o que é dito por meio da própria enunciação.

A partir dessa observação, podemos dizer que o ethos do discurso da auto-ajuda é o do homem confiante e seguro, do homem que acredita plenamente em si, em seu potencial, e no seu próprio discurso, daí a certeza que revela ao enunciar e o modo como se compromete com o que diz.

Para compreendermos melhor o papel desse ethos no processo de adesão do destinatário ao discurso da auto-ajuda, investigamos as condições de desenvolvimento e expansão desse tipo de literatura, o que nos permitiu verificar que o homem confiante e seguro da 
auto-ajuda vai ao socorro do indivíduo inseguro e em crise, típico da sociedade pós-moderna. Esse indivíduo busca uma solução para a angústia causada especialmente pelas rápidas transformações (sociais, culturais, econômicas, políticas e técnico-científicas) das sociedades pós-modernas, que criam um mundo essencialmente instável, responsável por vários efeitos negativos na vida psíquica dos indivíduos. Isso ocorre porque a efemeridade, a volatilidade e a descartabilidade - de coisas e pessoas - que caracterizam o mundo atual, tornam precários e transitórios os sistemas de valores públicos e pessoais, intensificando o processo de fragmentação do indivíduo. Esse, por sua vez, vai encontrar, na auto-ajuda, um porto-seguro, tendo em vista que o ethos desse discurso funciona como uma espécie de contraponto para a fragmentação e a insegurança que o caracterizam. Com o ethos de certeza e de confiança, a auto-ajuda cria uma atmosfera, ou melhor, um cenário de estabilidade, apresentando-se como uma espécie de tábua de salvação para o instável indivíduo pós-moderno, cujas referências estão abaladas.

Conforme vimos, Maingueneau nos diz que a formação discursiva, ao dar corpo à figura do sujeito-enuciador, confere, correlativamente, corporalidade também à figura do destinatário, isto é, ela também lhe dá corpo textualmente. No caso da literatura de auto-ajuda, com o ethos do homem confiante e seguro que orienta o seu destinatário no caminho do sucesso, cria-se a figura de um destinatário desorientado, carente de direcionamentos ${ }^{6}$ ou, como dizem Fornari \& Souza (2001): "O leitor é constituído numa posição de sujeito dominado, doente, necessitando de auxílio e de que lhe digam como deve proceder nos mais diversos setores de sua existência" (p. 138-9; o grifo é nosso).

Essa imagem do destinatário pode ser apreendida em alguns enunciados, especialmente interrogações, nos quais o interlocutor é interpelado diretamente pelo sujeito-enunciador por intermédio do pronome "você". Conforme mostram os exemplos abaixo, podemos perceber nesses enunciados a imagem do destinatário como uma pessoa infeliz, ou carente, ou insatisfeita com a vida. Qualquer que 
seja o adjetivo, é essencialmente alguém cuja imagem justifica a necessidade de orientação:

(01) E eu espero que, desde já, você comece a repensar: até quando você vai permitir que sua vida seja medíocre; até quando vai permitir que você seja infeliz; até quando vai se permitir não viver um grande amor; até quando vai se permitir trabalhar naquilo que (sic) não gosta; até quando vai se permitir viver com pouco dinheiro; até quando? Até quando? Até quando? (RICARDINO, 1997, p. 18)

(02) (...) até quando você quer continuar sendo um cachorrinho, dependente, limitado, esperando pela aceitação do outro? (ibid., p. 76)

(03) Agora olhe dentro de você. Tente perceber como está se sentindo neste exato momento. Como estão indo aqueles sonhos acalentados há tantos anos? Foram realizados plenamente? Parcialmente? Foram "arquivados"? Deram lugar a opções mais "reais"? Foram adiados para alguma ocasião mais propícia? Ou continuam piscando em certos momentos, no painel dos seus pensamentos mais íntimos? Você se sente satisfeito com o que já conquistou na vida? Almeja mais? Acredita nas usas chances? O que está faltando, afinal, para que você consiga ser realmente bem-sucedido? (RIBEIRO, 1992, p. 7 e 9).

A auto-ajuda também sustenta que quem tem uma atitude positiva consegue o que quer e prospera; já quem tem uma atitude negativa não só não prospera como também atrai situações desagradáveis. Por isso, esses livros sugerem aos seus interlocutores que assumam uma atitude positiva perante a vida, adotando uma forma ideal de formular os pensamentos e de enunciar que se encontra mais ou menos explícita nessa literatura. Isso porque, segundo tais obras, as palavras, sejam aquelas que constituem os nossos diálogos interiores, sejam aquelas que exteriorizamos, têm poder criativo, que consegue produzir qualquer tipo de situação, tanto boa quanto má. Vejamos algumas passagens a esse respeito: 
(04) Essa é a parte mais bonita e mais perigosa porque, ao mesmo tempo em que você pode criar uma situação muito boa, você pode criar também uma situação muito ruim, com base naquilo que você deseja, naquilo que (sic) acredita, naquilo que (sic) pensa e naquilo que fala. (RICARDINO, 1997, p. 25)

(05) Deveis saber que as vossas palavras e pensamentos são tremendas forças vibratórias, que estão continuamente amoldando o vosso corpo e os vossos negócios. (PRADO, 1995, p. 25)

(06) Vamos começar com a comunicação interior, isto é, a sua comunicação consigo mesmo. Neste caso, a linguagem que usamos é de fundamental importância para conseguirmos o que desejamos. (RIBEIRO, 1992, p. 64)

Outras características desse modelo de pensar/enunciar, além da certeza, são a clareza e a objetividade. Como a nossa mente reproduz tudo o que pensamos/dizemos, devemos saber exatamente o que queremos e nos concentrar nisso, descartando o que não desejamos, para que isso não nos aconteça. Como esclarece Ribeiro, é preciso evitar as frases negativas, pois

"o inconsciente vai direto ao assunto. O assunto de uma frase negativa não é o não. Então, ele omite os 'nãos'. Por exemplo, não pense na cor vermelha!!! Não pense numa maçã!!! Como você já percebeu, já é muito tarde. Mesmo sublinhando o 'não pense', você certamente pensou no vermelho e na maçã. Talvez, até mesmo, numa maçã vermelha! O mesmo acontece quando você diz 'Eu não quero falhar: o subconsciente registrará 'falhar' e você, sem perceber, está fazendo tudo para falhar' “ (ibid., p. 65).

Daí a necessidade de formular o pensamento e o que se diz com objetividade e assertividade, para não atrair justamente o que é indesejado. Nesse sentido, podemos dizer que, na auto-ajuda, a "objetividade" é entendida como um sinônimo de direcionamento, de priorizar o que interessa; assim, pensar/enunciar com objetividade é direcionar o pensamento/enunciação exatamente para o que se almeja, focalizando somente o que se quer. 
Como no caso da certeza, essa objetividade proposta pela autoajuda também pode ser percebida na própria enunciação do seu sujeito-enunciador; afinal, a literatura de auto-ajuda é mais um conjunto de orientações, de direcionamentos do que um convite à reflexão. Por isso, podemos dizer que essa literatura, à sua maneira, "também vai direta ao assunto", ao apresentar, ao lado de um conjunto relativamente pequeno de teses (que se repetem constantemente por meio de paráfrases), um conjunto de enunciados que orientam o interlocutor em seu caminho rumo ao sucesso. Isso explica a grande quantidade de enunciados imperativos que se encontra nessa literatura. Espécie de manual de sobrevivência para o homem pós-moderno, a auto-ajuda dispensa as discussões de suas teses ao apresentá-las, conforme dito, como verdades inquestionáveis e, no lugar da reflexão acerca do que propõe, oferece ao seu interlocutor "verdadeiras receitas contra a angústia, o medo, a incerteza, a falta de confiança própria e outros obstáculos que, somados, resultam no 'atraso de vida' "(PRADO, 1995, contra-capa). Como nos esclarecem Fornari e Souza: "A literatura de auto-ajuda busca dar respostas às incertezas do sujeito contemporâneo que, perdendo as antigas referências, precisa que lhe digam como fazer as coisas, como gerir suas vidas" (idem, p. 140).

Assim, a maneira como a literatura de auto-ajuda apresenta suas teses implica numa atitude a-crítica. Esse modo de enunciar "objetivo", que vai quase autoritariamente ao socorro do indivíduo pós-moderno tão carente de aconselhamentos, condiz exatamente com o que a auto-ajuda prega por meio de enunciados como "Concentrar-se no que você não quer, ao invés de concentrar-se no que você quer, é como dirigir um carro olhando pelo retrovisor" (RIBEIRO,1992, p. 64).

Essa característica enunciativa do discurso da auto-ajuda também é detectada por Chagas. Nas palavras do autor:

"Os conteúdos discursivos dessas literaturas produzem um nível de
atração caracteristicamente autoritário em sua imponência e
convicção. Não existe interesse pela reflexão do pensamento 
critico, visto que sua proposta é a de dar certo, jamais falhar.(...) Mais do que demonstrar, esse discurso visa fascinar, nada mais, nada menos, do que pelas expressões maravilhosas de seus líderes (...). As palavras ou frases proferidas orientam o sujeito para as ações. Assim, todo e qualquer orador que vem promover o otimismo e a motivação pela auto-ajuda, não permite sequer uma análise ou reflexão crítica sobre as fórmulas e técnicas ensinadas. O que os líderes fascinadores da auto-ajuda indicam, através de seus discursos (muitas vezes provocativos), é que todos os sonhos, isto é, todas as ilusões, podem tornar-se realidades, de forma semelhante, como acontece nos contos de fadas e como num passe de mágicas (...).” (CHAGAS, 1999, p. 75; o grifo é nosso)

Considerando esse modo de enunciar que privilegia "o que interessa", entendemos por que encontramos em muitos livros de auto-ajuda, no final dos capítulos, um resumo do que foi dito ou ainda, ao longo dos capítulos, frases em negrito, destacadas do corpo do texto. Esses procedimentos textuais não só reforçam as teses apresentadas, como também destacam o que elas têm de principal, apontando aos seus interlocutores um atalho para a própria "essência" do texto.

É interessante destacarmos que clareza e/ou objetividade são propriedades que os próprios textos de auto-ajuda se atribuem ou que lhes são atribuídas pelos textos periféricos que os acompanham na mesma publicação (por exemplo: contra-capas, orelhas, prefácios, etc.). Vejamos algumas passagens a esse respeito:

(07) Este livro se propõe a ser prático e objetivo (...). (RIBEIRO, 1992, p. 49)

(08) Neste livro, Arthur Riedel, verdadeiro professor de otimismo, expõe, em linguagem clara e atraente, uma filosofia prática de vida baseada na auto-sugestão mental e no desenvolvimento da vontade. (PRADO, 1995, p. 159)

(09) O livro Pense Fale Exista trata desses assuntos de maneira prática e simples. Ensina de modo direto como ser eficaz na comunicação. (...) A obra, na sua linguagem objetiva (...). (MOYSES \& RIBAS, 1998, p. 8) 
Vejamos agora os seguintes enunciados:

(10) A vida que você leva foi criada por você. (RIBEIRO, 1992, p. 117)

(11) Tudo que acontece na sua vida foi você que criou. (RICARDINO, 1997, p. 25)

(12) "VOCÊ É AQUILO QUE VOCÊ PENSA" - lembre-se disso. Cada um cria o seu mundo mental através dos seus pensamentos positivos ou não, e tem que viver rodeado pelas conseqüências daquilo que criou. (ROCHA, 1995, p. 10)

A partir dos enunciados citados, podemos dizer que, na verdade, a literatura de auto-ajuda não se dispensa apenas de apresentar uma reflexão mais profunda a respeito das teses que apresenta. Por intermédio da sua tese a respeito da responsabilidade que os homens têm sobre os seus destinos, ela se coloca numa posição privilegiada na qual não há a necessidade de oferecer qualquer reflexão a respeito dos inúmeros problemas do mundo pósmoderno e de seus efeitos nos indivíduos nele inseridos. Assim, a literatura de auto-ajuda, ao invés de discutir causas, oferece receitas de soluções e, com elas, promete a metamorfose de um indivíduo fraco e inseguro em alguém todo poderoso, capaz de resolver todos os seus problemas independentemente do contexto em que está inserido.

Uma outra característica do discurso de auto-ajuda é seu tom otimista. Afirmando que "semelhante atrai semelhante" (RIBEIRO, 1992, p. 58), a auto-ajuda sustenta que devemos pensar única e exclusivamente em coisas positivas para que, com pensamentos de sucesso, consigamos finalmente atraí-lo. Ela mesma, seguindo a orientação que propõe, apresenta aos seus interlocutores somente frases de otimismo e esperança, descartando qualquer referência aos problemas do mundo. Cria-se, com isso, uma atmosfera de confiança, na qual os interlocutores podem encontrar um amparo para a insegurança que os aflige. Vejamos algumas passagens que refletem o tom otimista do discurso da auto-ajuda: 
(13) Então, chegamos a uma primeira boa notícia neste livro, afinal você começa a descobrir que não é quem você pensa que é. Opa, ótimo! Então aquelas limitações, aquela infelicidade podem acabar. É só você levar isso adiante (...). (RICARDINO, 1997, p. 28)

(14) Todas as crianças podem ser superdotadas, se forem estimuladas para tal. O mais bonito desta história é que isso pode ser feito não só na infância, mas em qualquer momento da vida, desde que se conheça a estratégia correta. A sua história pode mudar positivamente, a caminho do sucesso e do pleno uso da sua potencialidade, a partir de hoje. (RIBEIRO, 1992, p. 31)

(15) Adquiri (sic) o hábito de proceder dessa forma e vereis as maravilhas e os milagres se apresentarem continuamente em vossas vidas. (PRADO, 1995, p. 55)

(16) Acredite que você pode. Seu potencial é infinitamente grande. Seu poder de conseguir tudo o que você "realmente" deseja é infinito, assim como infinita é a sua imaginação e o seu poder criador. Vamos, pense, crie, deseje. (ROCHA, 1995, p. 133)

Da mesma forma como faz com relação às demais características, verificamos que o discurso da auto-ajuda segue exatamente o que sugere aos seus destinatários com enunciados do tipo:

(17) Por esse motivo, para alterardes vossa atitude mental e vossos sentimentos internos, transformando-os em pensamentos otimistas, alegres e elevados, convém falardes (sic) no mesmo tom e proferirdes (sic) somente palavras animadoras e construtivas. (PRADO, 1995, p. 44; o grifo é nosso)

Na verdade, alguns livros de auto-ajuda vão ainda mais longe, pois, além de dispensarem qualquer referência aos problemas relativos ao indivíduo pós-moderno, reforçam essa atmosfera de otimismo construindo uma imagem positiva do mundo em que vivemos, conforme revelam os enunciados abaixo: 
(18) Não tem nada de errado com o mundo em si. O caso não é mudar o Brasil, nem a sociedade. Você é quem tem que mudar. (RIBEIRO, 1992, p. 42)

(19) Vivemos e trabalhamos num sistema onde tudo é possível. Basta ousar e querer. (ibid., p. 114)

Essa imagem positiva do mundo também ajuda a reforçar o cenário de estabilidade que a auto-ajuda oferece aos seus interlocutores, ao qual nos referimos anteriormente.

Dessa forma, podemos dizer que a auto-ajuda, por intermédio do cenário estável e otimista que constrói, está, ao seu modo, combatendo o mundo efêmero e instável das sociedades pósmodernas ${ }^{7}$, anunciando aos seus interlocutores "um novo mundo novo, cheio de esperanças e felicidades" ${ }^{8}$, no qual tudo é possível e cada um pode realizar todos os seus sonhos. Dizendo somente o que é interessante aos seus interlocutores, o discurso em questão é "preenchido (...) por palavras e frases persuasivas que, de modo geral, não provocam desacordo em ninguém” (CHAGAS, 1999, p. 75), daí o sucesso desse tipo de literatura.

O conjunto das observações que fizemos até aqui (relativas ao modo direcionado/objetivo de enunciar da auto-ajuda) nos permite dizer que o ethos desse discurso, além de ser o do homem confiante e seguro, também é o do homem objetivo/direcionado, que vai direto ao que interessa (no caso, orientar devidamente o seu destinatário para que esse alcance o sucesso). Essa imagem condiz com o ideal de agir que a auto-ajuda promove em seus textos, ao afirmar que aquele que almeja o sucesso deve estar consciente de que é o responsável pelo próprio destino, voltar para si e assumir o controle da vida, fazendo o que precisa ser feito para alcançar os seus objetivos, isto é, deve direcionar-se para a construção do próprio sucesso. Nesse sentido, a auto-ajuda promove o homem determinado, que arregaça as mangas e age, que faz o que é preciso para o seu próprio benefício, daí os enunciados que valorizam a ação, ofazer. A seguir, citamos alguns: 
(20) Para ter sucesso na vida, um dos segredos é fazer as coisas acontecerem. Conversa não adianta. (RIBEIRO, 1992, p. 107)

(21) Ou seja, não basta querer, é preciso fazer acontecer. (RICARDINO, 1997, p. 52)

(22) O melhor modo de diminuir a ansiedade é agir rápido. (MOYSES \& RIBAS, 1998, p. 97)

Por meio das passagens citadas a seguir, percebemos mais claramente como esse homem de ação deve ser centrado em si e em seus interesses e fazer o que lhe é conveniente; afinal, assim como devem ser objetivos/direcionados os seus pensamentos e as suas palavras, também devem ser objetivas/direcionadas suas ações:

(23) O negócio é fazer a coisa bem feita. E fazer a coisa certa. Com esta simples mudança de atitude, você pode passar a ganhar mais dinheiro e a ter muito sucesso em suas atividades. Sempre que estiver pronto para iniciar qualquer atividade, pergunte a si próprio: isso precisa realmente ser feito? E não gaste nisso a sua energia se a resposta for "não”. (RIBEIRO, 1992, p. 110; o grifo é nosso)

(24) Mas, para isso precisamos: ter consciência do que não está bem; saber onde (sic) queremos chegar, o motivo por que queremos mudar; fazer alguma coisa para isso. (RICARDINO, 1997, p. 52; o grifo é nosso)

(25) Após refletir sobre a situação e constatar que nada se pode fazer, evite desgastar-se inutilmente tentando fazer coisas fora de seu alcance. Trabalhe a seu favor. Quando não for possível fazer nada, devemos desfocar nossa atenção do problema, para nosso próprio bem mental e físico. (MOYSES \& RIBAS, 1998, p. 102; o grifo é nosso)

O ethos da auto-ajuda, além de ser o ethos do homem direcionado, é também o do homem persistente, que não desanima 
diante dos problemas da vida. Ao contrário, ele os considera, numa atitude que revela todo o seu otimismo, como oportunidades de crescimento, conforme nos revelam as passagens abaixo:

(26) Quando eu entendo essa origem, quando eu acredito nessa origem, as coisas da minha vida vão ficar muito mais fáceis. As dificuldades que eu encontro vão ser mais fáceis de ser superadas. Na verdade, elas não são dificuldades, são desafios no aprendizado. (RICARDINO, 1997, p. 64)

(27) No momento em que passar a aprender com o problema, a vida vai ficar muito melhor. Por isso eu costumo dizer a essas pessoas que gostam de se lamentar: - Os problemas são nossos melhores amigos. (RIBEIRO, 1992, p. 96)

Sustentando a tese de que "se a situação não é favorável é preciso mudar", a auto-ajuda promove a necessidade de quebrar paradigmas ${ }^{9}$, daí a existência de enunciados do tipo:

(28) (...) para que você possa transformar alguma coisa na sua vida são importantes dois aspectos: o primeiro é ter consciência, é saber; o segundo é agir, é fazer algo para mudar o antigo. (RICARDINO, 1997, p. 33)

(29) O sucesso significa nunca parar, ou seja, sempre ir em busca de algo mais. A estrela do sucesso está sempre em movimento. (RIBEIRO, 1992, p. 29)

(30) Se você continuar fazendo o que sempre fez, vai continuar conseguindo o que sempre conseguiu. Se você quer coisas diferentes, tem que fazer alguma coisa diferente. (ibid., p. 112)

Nesse sentido, o ideal de agir promovido pela auto-ajuda é caracterizado pela flexibilidade, pela versatilidade, qualidades valorizadas nesse tipo de literatura, conforme atestam as passagens a seguir: 
(31) Nos Estados Unidos, os filhos de pessoas ricas aos 16 anos de idade já estão trabalhando, seja em postos de gasolina, como garções ou qualquer outro emprego do tipo, essa situação é considerada absurda no Brasil. O americano aprende a ser versátil. Ele muda de profissão cinco vezes, em média, durante a vida. Muda 13 vezes de casa. Isto o faz pensar de forma diferente. (RIBEIRO, 1992, p. 88; o grifo é nosso)

(32) Se você não for flexível, não se conhecer e não souber que pode fazer mais coisas do que pensa que pode, vai ficar para trás. Então, uma pessoa que se conhece bem vai estar bem no futuro? Vai. E quem for rígido, quem for inflexível, quem não acreditar na sua parte afetiva, no auto-conhecimento, vai ficar para trás, se já não está hoje. (RICARDINO, 1997, p. 66; o grifo é nosso)

Num certo sentido, podemos dizer que essa versatilidade que os autores de auto-ajuda pregam como uma qualidade necessária à vida, também é uma propriedade de seus textos, pois esses apresentam uma grande quantidade de: esquemas, ilustrações, testes, citações das mais distintas origens (que vão da Bỉblia a Shakespeare) e pequenas narrações nas quais são contados episódios da vida do autor ou de outras pessoas. Todos esses procedimentos imprimem um tom versátil aos textos na medida em que são distintos recursos para reforçar e sustentar as teses apresentadas. Utilizando procedimentos de naturezas bem diferentes, os textos de auto-ajuda conseguem reforçar o que dizem, camuflando, de um certo modo, a repetição do conteúdo.

Por outro lado, ao propor uma forma ideal de habitar o mundo, o discurso da auto-ajuda constrói automaticamente o ethos que rejeita. Trata-se do ethos do homem inseguro, que deixa as oportunidades passarem com o tempo; do homem que não acredita em si, que, ao invés de fazer, perde tempo se lamentando, que encontra desculpas para a sua passividade diante dos fatos, postergando os projetos ou culpando o mundo e as coisas que estão ao seu redor pelo próprio 
fracasso. A esse respeito, destacamos as passagens abaixo, em algumas das quais o sujeito-enunciador apresenta, por meio de discurso direto (às vezes em itálico ou demarcado por aspas) o que seria o tipo de enunciação que rejeita:

(33) Alguns dizem: ah, não vou conseguir fazer, isto é impossível. $\mathrm{E}$, pensando assim, mesmo que façam e se esforcem, não conseguem, porque não acreditam. (RIBEIRO, 1992, p. 113)

(34) Acontece que a maioria das pessoas reage assim: "Não está bom, quero mudar, para onde não sei. Ah, mas vou ter que fazer tal coisa, dá muito trabalbo". Então, a pessoa fica na passividade, na acomodação e realmente não muda. (RICARDINO, 1997, p. 52)

(35) Conheci uma senhora que vivia contando por toda parte seus aborrecimentos. Andava espalhando para todo mundo: "Sei o que é sofrimento!" - e ficava esperando palavras de simpatia. Certamente, quando mais mencionava os seus aborrecimentos, mais os aumentava, (...). (PRADO, 1995, p. 130)

Assim, de um lado temos o homem criado pelo ethos da autoajuda: seguro, confiante, otimista e direcionado, e, por outro lado, temos o homem inseguro, desanimado, lamentador, submisso às circunstâncias, que duvida de si e de seu potencial.

\section{CONSIDERAÇÕES FINAIS: A AUTO-AJUDA E O INDIVIDUALISMO}

Neste trabalho, procuramos definir o ethos do discurso da autoajuda a partir das características enunciativas desse discurso. Verificamos, inicialmente, que esse discurso explicita um certo ideal de enunciar cujas características se reproduzem na sua própria enunciação, isto é, o discurso da auto-ajuda manifesta o tipo de enunciação que promove. A partir daí, pudemos traçar o perfil do sujeito-enunciador. Como as características essenciais da enunciação da auto-ajuda são a manifestação da certeza e o direcionamento para os pontos principais, verificamos que o ethos da auto-ajuda é o do 
homem seguro, autoconfiante, determinado e autocentrado, isto é, voltado para os seus objetivos e interesses, agindo em busca de seu próprio bem. Nesse sentido, o homem que corresponde ao ethos da literatura de auto-ajuda encarna o tipo ideal de homem individualista, cujo surgimento está ligado aos mesmos fatores que deram origem a esse tipo de literatura. Esse homem individualista, decantado pela modernidade, é

"liberto das limitações da tradição podendo, então, cultivar-se pela própria razão, uma razão egocentrada que busca afastar-se dos compromissos sociais e imprimir na existência do sujeito um compromisso único com a busca do prazer, a partir da autoconstrução" (FORNARI \& SOUZA, 2001, p. 135, o grifo é nosso).

Desse modo, a auto-ajuda, projetando a imagem de um homem confiante em seu poder de autoconstrução, ajuda a sustentar o individualismo que a engendrou, ou melhor, ela contribui "para a reprodução da sociedade capitalista neoliberal, caracterizada pelo individualismo possessivo e pelo narcisismo" (ibid., p. 140).

Por fim, podemos dizer que a auto-ajuda é um discurso fechado sobre si próprio. Assim como o homem ideal que define está voltado para a construção de si mesmo, esse discurso centra-se no que considera mais importante, isto é, o oferecimento de orientações concomitantemente à sustentação de suas teses. Como uma sala de espelhos, na qual o conteúdo dos enunciados coincide com as características da enunciação, a auto-ajuda apresenta, em seu ethos, o reflexo do ideal de ser/agir que ela promove. 


\section{NOTAS}

1 "Seriam" e não "são" porque, segundo Maingueneau, cada discurso introduz o Outro em seu fechamento, traduzindo os enunciados desse Outro nas suas próprias categorias, o que significa que a relação que um discurso assume com o seu Outro, nunca é com o Outro em si, mas com o simulacro que dele constrói.

${ }^{2}$ Cf. MAINGUENEAU, 1995, p. 139.

${ }^{3}$ MAINGUENEAU, 1995, p. 139.

${ }^{4}$ MAINGUENEAU, 1989, p. 54.

${ }^{5}$ BRUNELLI, 2002.

${ }^{6}$ Em HARVEY (1992), a necessidade de aconselhamentos é apontada como uma das características do indivíduo pós-moderno.

${ }^{7}$ Cf. CHAGAS, 1999, p. 32.

8 idid., p. 77.

${ }^{9}$ Cf. RIBEIRO, 1992, cap. XIV.

\section{REFERÊNCIAS BIBLIOGRÁFICAS}

BRUNELLI, A. F. A modalidade na literatura de auto-ajuda. Alfa. São Paulo, 47 (2), p. 117-137, 2003.

CHAGAS, A. T. S. A ilusão no discurso da auto-ajuda e o sintoma social. Ijuí: Ed. UNIJUÍ, 1999.

EAGLETON, T. Ideologia. São Paulo: Boitempo/Editora da UNESP, 1997.

FORNARI, L.M.S. \& SOUZA, E.C. As narrativas nos discursos de auto-ajuda. Salvador: Revista da FAEEBA, n. 15, p. 133-141, jan/jun, 2001.

HARVEY, D. Condição pós-moderna. São Paulo: Loyola, 1992.

MAINGUENEAU, D. Semantiqué de la polemiqué. Lausanne: L'Age d'homme, 1983.

. Novas tendências em Análise do Discurso. Campinas: Pontes/Ed. da UNICAMP, 1989. . O contexto da obra literária. São Paulo: Martins Fontes, 1995. 
MAINGUENEAU, D. El ethos y la voz de lo escrito. Versión: estudios de Comunicación y política. México: Universidad Autónoma MetropolitanaXochimilco, n. 6, p. 79-92, 1996.

1998. Gènése du discours. Tradução manuscrita de Sírio Possenti. Campinas,

PRADO, L. Alegria e triunfo. São Paulo: Pensamento, 1992.

RIBAS, A. B. S. \& MOYSES, C. Pense Fale Exista. São Paulo: AutoData, 1998.

RIBEIRO, L. O sucesso não ocorre por acaso. Rio de Janeiro: Rosas dos Tempos, 1992.

RICARDINO, L. Parabéns pela decisão de ser feliz: a busca do ser. São Paulo: STS, 1997.

ROCHA, A. ABC do poder da mente. Rio de Janeiro: Nórdica, 1995. 